EKONOMI POLITIK INSTITUSI ZAKAT: SATU PENELITIAN TERHADAP INSTITUSI ZAKAT DI PULAU PINANG

Mohammad Najwa

PRAKTIK KURBAN ONLINE DALAM PERSPEKTIF ISLAM TEBAR HEWAN KURBAN THK DI DOMPET DHUAFA

Reni Noviati

WAKAF SAHAM DITINJAU DARI HUKUM ISLAM DAN PERATURAN PERUNDANGUNDANGAN SETELAH BERLAKUNYA UNDANG-UNDANG NOMOR 41

TAHUN 2004 TENTANG WAKAF

Gusva Havita dan Gestivia Hakim

KARAKTERISTIK ENTREPRENEUR SYARIAH PADA USAHA MIKRO, KECIL, DAN MENENGAH (UMKM) DI BOGOR

Siti Usniah dan Anas Alhifni

ALTERNATIF SOLUSI ATAS PROBLEMATIKA PEMBIAYAAN MUDHARABAH

Rafidah

FAKTOR-FAKTOR YANG MEMPENGARUHI MOTIVASI MAHASISWA MENJADI ENTREPRENEUR SYARIAH

Nur Maulida Hidayat dan Anas Alhifni 
Ketua Editor :

Tuti Kurnia, SP., M.Si

Editor Pelaksana :

H. Sofian Muhlisin, LLB., LLM

Furqonul Haq, SEI., M.EI

Journal Manager :

Wildan Munawar, SEI

Jurnal Syarikah: Jurnal Ekonomi Islam adalah jurnal ilmiah yang diterbitkan untuk mendukung pengembangan ekonomi Islam. Jurnal Syarikah akan memuat artikelartikel yang terkait dengan kajian ekonomi Islam baik kajian teoritis maupun praktis. Redaksi menerima sumbangan artikel, tulisan ilmiah dari para peminat ilmiah kajian ekonomi dan keuangan syariah. Proses editing seperlunya tanpa mengubah maksud dan kandungan tulisan tersebut.

Alamat Redaksi :

Fakultas Ekonomi Islam

Universitas Djuanda Bogor

Gedung B Lantai 4

Jl. Tol Ciawi No.1 Ciawi Bogor Kode Pos 16720

Telp. (0251) 8240985

Email : fei@unida.ac.id 


\section{DAFTAR ISI}

EKONOMI POLITIK INSTITUSI ZAKAT: SATU PENELITIAN TERHADAP INSTITUSI ZAKAT DI PULAU PINANG

Mohammad Najwa

PRAKTIK KURBAN ONLINE DALAM PERSPEKTIF ISLAM TEBAR HEWAN KURBAN THK DI DOMPET DHUAFA

Reni Noviati

WAKAF SAHAM DITINJAU DARI HUKUM ISLAM DAN PERATURAN PERUNDANG-UNDANGAN SETELAH BERLAKUNYA UNDANG-UNDANG NOMOR 41 TAHUN 2004 TENTANG WAKAF

Gusva Havita, Gestivia Hakim

KARAKTERISTIK ENTREPRENEUR SYARIAH PADA USAHA MIKRO, KECIL DAN MENENGAH (UMKM) DI BOGOR

Siti Usniah, Anas Alhifni

ALTERNATIF SOLUSI ATAS PROBLEMATIKA PEMBIAYAAN MUDHARABAH

Rafidah

FAKTOR-FAKTOR YANG MEMPENGARUHI MOTIVASI MAHASISWA MENJADI ENTREPRENEUR SYARIAH

Nur Maulida Hidayat, Anas Alhifni 


\title{
EKONOMI POLITIK INSTITUSI ZAKAT: SATU PENELITIAN TERHADAP INSTITUSI ZAKAT DI PULAU PINANG
}

\section{POLITICAL INSTITUTIONS OF CHARITY ECONOMY: THE RESEARCH INSTITUTIONS OF CHARITY IN PENANG}

\author{
M. Najwa1a \\ 1aPoliteknik Seberang Prai dan Pusat Kajian Pengurusan Pembangunan Islam (ISDEV), \\ Universitas Sains Malaysia, Pulau Pinang, Email: mohdnajwa16@gmail.com
}

\begin{abstract}
The study was conducted to identify and analyze the political economy of charity institutions in Penang. This study was performed using two methods of data collection, namely the first, methods study the document; and second, the interview method. The data collected is then analyzed using content analysis. The results of the analysis, it can be concluded three things. First, the establishment of Zakat Pulau Pinang (ZPP) is a strategy Majlis Agama Islam Negeri Pulau Pinang (MAINPP) to strengthen the political economy of charity institutions in Penang. Second, the economy and politics mutually need each other in charity governance institutions in Penang. Third, the political economy of charity institutions in Penang has made zakat governance in Penang more systematic and professional and have a positive impact on the improvement of collection and distribution of zakat in Penang.
\end{abstract}

Keywords: Political Economy, Political Economy Institutions Zakat, Zakat Institution in Penang

\begin{abstract}
ABSTRAK
Penelitian ini dilakukan untuk mengenal pasti dan menganalisis ekonomi politik institusi zakat di Pulau Pinang. Kajian ini dilakukan dengan menggunakan dua kaedah pengumpulan data yaitu pertama, kaedah kajian dokumen; dan kedua, kaedah temu bual. Data-data yang dikumpul itu kemudiannya dianalisis dengan menggunakan kaedah analisis kandungan. Hasil daripada analisis, dapat dirumuskan tiga perkara. Pertama, penubuhan Zakat Pulau Pinang (ZPP) merupakan strategi Majlis Agama Islam Negeri Pulau Pinang (MAINPP) bagi mengukuhkan ekonomi politik institusi zakat di Pulau Pinang. Kedua, ekonomi dan politik saling memerlukan antara satu sama lain dalam tadbir urus institusi zakat di Pulau Pinang. Ketiga, ekonomi politik institusi zakat di Pulau Pinang telah menjadikan tadbir urus zakat di Pulau Pinang semakin sistematik dan profesional serta memberi kesan yang positif terhadap peningkatan kutipan dan agihan zakat di Pulau Pinang.

Kata Kunci: Ekonomi Politik, Ekonomi Politik Institusi Zakat, Institusi Zakat Di Pulau Pinang
\end{abstract}

Najwa, Mohammad. 2017. Ekonomi Politik Institusi Zakat: Satu Penelitian Terhadap Institusi Zakat di Pulau Pinang. Jurnal Syarikah 3 (1): 330 - 342. 


\section{PENDAHULUAN}

Secara umumnya, ekonomi politik institusi zakat merupakan satu cabang ilmu yang mengkaji hubungan antara ekonomi dengan politik dalam mentadbir urus institusi kewangan umat Islam berkaitan zakat. Ekonomi politik institusi zakat adalah gabungan dua istilah yaitu ekonomi politik dan institusi zakat. Ekonomi politik didefinisikan sebagai hubungan antara ekonomi dengan politik dalam membangunkan ekonomi dan pentadbiran sesebuah negara (Devas, 2009). Menurut Mohd Syakir Mohd Rosdi (2012) pula, ekonomi politik ialah menganalisis ekonomi dan politik, agar interaksi antara ekonomi dengan pemerintah dalam memastikan kekayaan negara dapat dipertingkatkan sebagai syarat memenuhi kehendak sosial. Ekonomi politik tersebut mencakupi bidang sains politik dan menjangkaui ilmu sosial, budaya, hukum dan psikologi.

Institusi zakat pula merujuk kepada institusi Islam yang bertanggungjawab menguruskan kewangan masyarakat Islam terutama berkaitan dengan kutipan dan agihan zakat kepada asnaf untuk tujuan meningkatkan taraf kehidupan asnaf. Menurut Mujaini Tarimin (2009), institusi zakat merupakan institusi yang dilantik oleh kerajaan yang memerintah dalam sesebuah kerajaan Islam dan bertanggungjawab mengutip dan mengagihkan dana zakat kepada asnaf yang telah ditentukan dalam al-Qur'an dan Hadith serta ijtihad ulama. Shofian Ahmad dan Luqman Mahadi (2013) pula mendefinisikan institusi zakat sebagai wakil pemerintah untuk menguruskan segala urusan yang berkaitan dengan zakat yaitu mengumpul dan mengagihkan zakat kepada asnaf.

Di sesetengah negeri di Malaysia, pengurusan dan pentadbiran institusi zakat dilaksanakan oleh MAIN dan pentadbiran kerajaan negeri masing-masing sebagai wakil kepada DYMM Sultan atau Raja. Namun begitu, isu mengenai institusi zakat di Pulau Pinang lebih kompleks kerana pengurusan dan pentadbiran pada peringkat kerajaan negeri adalah diketuai oleh golongan bukan Muslim. Oleh yang demikian, kertas kerja ini berhasrat untuk meneliti hubungan antara ekonomi dengan politik dalam tadbir urus institusi zakat di Pulau Pinang, peranan dan strategi ekonomi politik institusi zakat di Pulau Pinang. Dengan menggunakan kaedah kajian dokumen, kaedah temu bual separa berstruktur dan kaedah analisis kandungan, maklumat berkaitan ekonomi politik institusi zakat di Pulau Pinang yang merangkumi interaksi antara ekonomi dengan politik dalam tadbir urus zakat di Pulau Pinang, peranan dan strateginya disusun dan dianalisis. Untuk lebih tersusun perbincangan dalam kertas kerja ini dibahagikan kepada lima bahagian. Bahagian pertama, tadbir urus institusi zakat di Pulau Pinang. Bahagian kedua, strategi ekonomi dan politik institusi zakat di Pulau Pinang. Bahagian ketiga, peranan politik dan ekonomi dalam institusi zakat di Pulau Pinang. Bahagian keempat, hubungan antara ekonom dan politik dalam institusi zakat di Pulau Pinang. Kelima, kesimpulan.

\section{MATERI DAN METODE}

\section{Tadbir Urus Institusi Zakat Di Pulau Pinang}

Pengurusan zakat di Pulau Pinang ditadbir urus oleh Majlis Agama Islam 
Pulau Pinang (MAINPP) bermula pada tahun 1960 berasaskan kepada UndangUndang Pentadbiran Agama Islam Negeri Pulau Pinang Tahun 1959 (Undang-Undang No. 3 Tahun 1959) yang diluluskan oleh Dewan Undangan Negeri Pulau Pinang pada 15 April 1959 (MAINPP, 2016). Undang-undang tersebut telah memperuntukan pembentukkan satu badan yang bertanggungjawab untuk membantu dan menasihati Duli Yang Maha Mulia Yang Dipertuan Agong dalam perkara-perkara berkaitan hal ehwal agama Islam di Pulau Pinang termasuklah hal-hal yang berkaitan dengan zakat (Abdullah: 2011). Sejak daripada penubuhan MAINPP pada tahun 1960 hingga tahun 1994, urusan kutipan dan agihan zakat di Pulau Pinang diuruskan di bawah satu bahagian di MAINPP.

Pada tahun 1994, MAINPP menubuhkan sebuah anak syarikat yaitu As-Sahabah Urus Zakat Bendirian Berhad (ASUZSB) yang didaftarkan sebagai syarikat petugas amil bagi pihak MAINPP dengan pelaburan modal sejumlah RM 1,019,658.00. Syarikat tersebut diperbadankan sebagai syarikat sendirian berhad (Sdn. Bhd.) milik penuh MAINPP dengan kawalan modal sebanyak 100\% di bawah Akta Syarikat 1965 (Abdullah: 2011).

ASUZSB telah memulakan operasi sepenuhnya bermula 1 September 1994 dengan menggunakan nama Pusat Urus Zakat Pulau Pinang (PUZPP). Penggunaan nama PUZPP adalah untuk mengekalkan kepentingan awam terhadap institusi tersebut (Zakat Pulau Pinang, 2013). Menurut Mohamad Salleh Abdullah (2011) PUZPP merupakan icon bagi pengurusan zakat di Pulau Pinang dan bertujuan untuk meyakinkan masyarakat Islam di Pulau Pinang terhadap institusi zakat yang ditubuhkan. Pada ketika itu masyarakat Islam di Pulau Pinang tidak dapat menerima pengurusan dan pentadbiran zakat diswastakan atau dikorporatkan kepada sebuah institusi swasta (Noor: 2016). Sikap masyarakat yang sedemikian dibimbangi akan menjelaskan kutipan zakat di Pulau Pinang dan hasrat MAINPP untuk meninggikan kecekapan dan keberkesanan pengurusan zakat di Pulau Pinang akan gagal. Oleh yang demikian, nama PUZPP bukanlah satu entiti yang ditubuhkan di bawah mana-mana undangundang perbadanan syarikat, malah ia merupakan satu jenama (branding) bagi mempromosikan pengkorporatan atau penswastaan zakat di Pulau Pinang (Salleh: 2016).

Pada peringkat awal penubuhannya, bidang kuasa PUZPP hanyalah sekadar mengumpulkan zakat harta di sekitar Pulau Pinang dan Seberang Perai sahaja. Pada masa yang sama, MAINPP masih memainkan peranan untuk mengumpulkan zakat fitrah dan mengagihkan dana zakat di negeri Pulau Pinang. Namun, kejayaan PUZPP meningkatkan kutipan zakat harta daripada RM 0.19 juta pada tahun 1994 kepada RM 9.36 juta pada tahun 1998 telah meyakinkan MAINPP bahawasanya PUZPP amat berpotensi untuk menguruskan operasi kutipan dan agihan zakat sekaligus. Bermula pada bulan Mac 1999, MAINPP telah memberi kepercayaan penuh kepada ZPP untuk menguruskan sepenuhnya kedua-dua operasi kutipan dan agihan zakat harta dan zakat fitrah di seluruh Pulau Pinang (Zakat Pulau Pinang, 2013).

Keputusan menyerahkan kuasa dan tanggungjawab memungut dan mengagihkan zakat di Pulau Pinang kepada PUZPP dibuat selepas tiga siri Muzakarah Pemantapan Sistem Agihan Zakat yang diadakan sejak tahun 1997 (Abdullah: 
2011). Keputusan tersebut menjadikan PUZPP sebagai institusi korporat yang pertama di Malaysia diluluskan dan diberi kuasa oleh MAIN untuk mengurus kutipan dan agihan zakat harta dan fitrah. Menurut Mohamad Salleh Abdullah (Temu bual bersemuka, 21 Jun 2016), penyerahan kuasa mengurus kutipan dan agihan zakat kepada syarikat korporat atau anak syarikat yang ditubuhkan khusus oleh MAINPP bertujuan untuk meningkatkan kecekapan dan keberkesanan pengurusan zakat di Pulau Pinang.

Nama korporat PUZPP diganti kepada nama korporat baharu yaitu Zakat Pulau Pinang (ZPP) selepas penjenamaan semula nama dan logo PUZPP, MAINPP. Penjenamaan semula PUZPP ini telah disempurnakan oleh TYT Tun Dato Seri Utama Dr Hj Abdul Rahman Hj Abbas, Yang Dipertua Negeri Pulau Pinang pada 26 April 2012 (Zakat Pulau Pinang, 2013).

\section{Metode Penelitian}

Kajian ini dijalankan berdasarkan dua kaedah pengumpulan data yaitu kaedah kajian kepustakaan (teoretikal) dan kaedah kajian lapangan (empirikal). Kedua-kedua kaedah kajian tersebut digunakan bagi mengumpul data primer dan data sekunder. Kajian kepustakaan dilakukan bertujuan mendapatkan data sekunder, manakala kajian lapangan pula dilaksanakan bertujuan mendapatkan data primer.

Kaedah kajian kepustakaan merupakan penelitian terhadap penulisan-penulisan yang berbentuk jurnal, artikel, laman web, buku-buku, laporan-laporan dan apa sahaja penulisan yang mempunyai kaitan dengan bidang kajian. Kajian kepustakaan juga merujuk kepada kaedah untuk mengumpul data melalui penelitian terhadap penulisanpenulisan sedia ada seperti penerbitan tempatan, penerbitan daripada luar negara, majalah, surat khabar, laporan tahunan dan laporan penyelidikan universiti (Bailey, 1984; Creswell, 2003; Othman Lebar, 2015). Kaedah kajian kepustakaan yang dilakukan dalam kajian ini adalah berkaitan ekonomi Islam, Politik Islam, ekonomi politik Islam dan tadbir urus institusi zakat di Malaysia.

Kaedah kajian lapangan pula merujuk kepada kaedah temu bual. Kaedah ini menggunakan kaedah temu bual separa berstruktur untuk mendapatkan maklumat yang lengkap dan mendalam bagi menjawab persoalan kajian. Responden temu bual akan ditentukan melalui kaedah persampelan bertujuan (purposive sampling). Proses pemilihan responden merupakan peringkat penting dalam sesuatu penyelidikan untuk mendapatkan data bagi memastikan maklumat yang diperolehi mencukupi dan menjawab persoalan kajian. Responden kajian yang dipilih perlulah mewakili populasi dan dapat memberikan gambaran terhadap populasi kajian. Bagi memperolehi data yang mencukupi dan menjawab persoalan kajian, temu bual akan melibatkan tiga kategori responden. Kategori pertama ialah golongan agamawan yaitu Mufti atau wakil Mufti. Kategori kedua ialah pihak yang terlibat secara langsung dalam pengurusan dan pentadbiran institusi zakat di Pulau Pinang. Kategori ketiga pula ialah Ahli Lembaga Pengarah Zakat Pulau Pinang.

Semua data yang dikumpul ini dianalisis dengan menggunakan kaedah analisis kandungan. Analisis dan interpretasi data merupakan proses akhir ketika melakukan kajian. Tidak ada satu ketetapan yang digariskan dalam melakukan penganalisisan data, namun penganalisisan data ini harus berdasarkan tahap kecekapan, kemampuan dan kebijaksanaan seseorang penyelidik. 


\section{HASIL DAN PEMBAHASAN}

\section{Strategi Ekonomi dan Politik Institusi Zakat di Pulau Pinang}

Secara umumnya, penubuhan syarikat ASUZSB merupakan strategi atau perancangan MAINPP bagi mengukuhkan ekonomi dan politik institusi zakat di Pulau Pinang. Menurut Mohamad Salleh Abdullah (Temu bual bersemuka, 21 Jun 2016), Mohamad Kairi Ghazali (Temu bual bersemuka, 3 Ogos 2016), Y.B. Dato' Abdul Malik Kassim (Temu bual bersemuka, 20 Oktober 2016) dan Mohd Noor Harun (Temu bual besemuka, 5 November 2016), terdapat empat strategi utama MAINPP menubuhkan dan melantik syarikat ASUZSB sebagai wakil amil di Pulau Pinang pada ketika itu. Pertama, memfokuskan peningkatan kutipan dan agihan zakat di Pulau Pinang; kedua, mengkorporatkan pengurusan zakat; ketiga, melayan pelanggan agar mereka rasa senang untuk berurusan dengan institusi zakat; keempat, bebas melantik sesiapa sahaja yang dikenal pasti layak untuk memegang jawatan tertinggi dalam institusi tersebut.

Selain daripada itu, menurut Wan Salim Wan Mohd Noor (Temu bual bersemuka, 27 Jun 2016), penubuhan ZPP telah menjadikan pengurusan dan pentadbiran zakat di Pulau Pinang lebih tersusun, sistematik dan berkesan. Pengurusan dan pentadbiran zakat sedemikian amat penting bagi meyakinkan masyarakat Islam di Pulau Pinang untuk berurusan dan membayar zakat kepada institusi zakat yang dilantik, bukannya membayar terus kepada asnaf. Penubuhan ZPP juga adalah untuk meringankan bebanan tugas MAINPP yang bertanggungjawab mengurus hal ehwal agama Islam di Pulau Pinang, pengurusan masjid, pengurusan wakaf dan tanah orang
Islam serta perkara-perkara yang berkaitan dengan masyarakat Islam di Pulau Pinang.

Menurut Y.B. Dato' Abdul Malik Kassim (Temu bual bersemuka, 20 Oktober 2016) dan Mohd Noor Harun (Temu bual besemuka, 5 November 2016), pada dasarnya strategi MAINPP menubuhkan ZPP sebagai sebuah syarikat swasta yang bertanggungjawab mengurus kutipan dan agihan zakat di Pulau Pinang adalah untuk mewujudkan pengurusan dan pentadbiran yang lebih agresif dan progresif. Menurut beliau, dalam kerangka syarikat swasta, pengurusan dan pentadbiran institusi tersebut lebih efektif kerana kuasa tadbir urusnya lebih terbuka. ZPP bebas untuk melantik sesiapa sahaja yang dikenal pasti untuk menjawat jawatan tertinggi dalam organisasi tanpa merujuk kepada Jabatan Perkhidmatan Awam (JPA). ZPP hanya putuskan dan dapatkan persetujuan dalam mesyuarat ALP serta mendapat persetujuan daripada EXCO Hal Ehwal Agama Islam Pulau Pinang.

Dato' IR. Ahmad Zakiyuddin Abd Rahman (Temu bual bersemuka, 3 November 2016) pula menyatakan strategi MAINPP melantik ZPP untuk mentadbir urus kutipan dan agihan zakat di Pulau Pinang adalah untuk memudahkan urusan pentadbiran kewangan dan pelantikan kakitangan ZPP serta menjadikan tadbir urus zakat di Pulau Pinang lebih sistematik dan tersusun. Sebagai sebuah syarikat Sdn. Bhd., ZPP berkuasa untuk melantik kakitangan, menentukan prosedur kerja, peraturan-peraturan dan berkuasa untuk menetapkan gaji pegawai ZPP.

\section{Peranan Ekonomi dan Politik dalam Institusi Zakat di Pulau Pinang}

Dari segi latar belakang politik, negeri Pulau Pinang agak berbeza dengan negerinegeri lain di Malaysia kerana pentadbiran 
Kerajaan Negeri Pulau Pinang diketuai oleh golongan bukan Muslim yaitu Yang Amat Berhormat (Y.A.B.) Tuan Lim Guan Eng daripada Parti Tindakan Demokratik (DAP) (Noor: 2016). Menurut beliau, pelantikan Y.A.B. Tuan Lim Guan Eng sebagai Ketua Menteri Pulau Pinang datang hasil daripada kesepakatan parti gabungan dalam Pakatan Rakyat yaitu Parti Keadilan Rakyat (PKR), Parti Tindakan Demokratik (DAP) dan Parti Islam Se-Malaysia (PAS) pada tahun 2008. Lantaran itu, urusan hal ehwal agama Islam di Pulau Pinang diletakkan di bawah bidang kuasa EXCO Hal Ehwal Agama Islam Pulau Pinang. Selain daripada hal ehwal agama Islam di Pulau Pinang, EXCO Hal Ehwal Agama Islam Pulau Pinang juga bertanggungjawab untuk mengawasi hal ehwal berkaitan kutipan dan agihan zakat di Pulau Pinang.

Secara umumnya, setiap institusi yang dilantik oleh pemerintah tidak boleh berfungsi dengan sendiri tanpa campur tangan kuasa pemerintah sama ada pada peringkat negara, negeri, penguasa agama ataupun institusi zakat itu sendiri (Abdullah: 2016). Menurut Rosidi Hussain (Temu bual bersemuka, 1 November 2016), peranan kuasa politik atau pemerintah dalam mana-mana institusi atau agensi Islam dan juga Jabatan Kerajaan di seluruh Malaysia pada hari ini memang tidak boleh dinafikan dan tidak boleh diasingkan. Dato' IR. Ahmad Zakiyuddin Abd Rahman (Temu bual bersemuka, 3 November 2016) juga mengatakan memang tidak dapat dinafikan bahawa terdapat pengawalan kuasa politik pemerintah terhadap institusi atau badanbadan yang ditubuhkan oleh pemerintah sama ada pada peringkat negara dan juga negeri. Kerajaan yang memerintah bertanggungjawab untuk memastikan mana-mana institusi atau badan-badan yang ditubuhkan untuk menguruskan hal ehwal rakyat mestilah selari dengan polisi dan dasar kerajaan yang memerintah.

Menurut Mohamad Salleh Abdullah (Temu bual bersemuka, 21 Jun 2016), ZPP merupakan sebuah institusi yang ditubuhkan oleh MAINPP untuk mentadbir urus kutipan dan agihan zakat di Pulau Pinang. Walaupun penubuhan ZPP adalah sebagai sebuah syarikat Sdn. Bhd., namun ZPP masih lagi di bawah pemantauan MAINPP dan juga EXCO Hal Ehwal Agama Islam Pulau Pinang yaitu Y.B. Dato' Abdul Malik Kassim. MAINPP merupakan sebuah institusi yang bertanggungjawab kepada EXCO Hal Ehwal Agama Islam Pulau Pinang dalam mengawasi dan menguruskan hal ehwal agama Islam di Pulau Pinang (Kassim: 2016).

Pada hakikatnya, kuasa politik pemerintah berperanan dalam tadbir urus zakat di Pulau Pinang sebagai mana yang dijelaskan oleh Mohamad Salleh Abdullah (Temu bual bersemuka, 21 Jun 2016). Menurut beliau, peranan kuasa politik pemerintah dalam tadbir urus institusi zakat tidak dapat dinafikan sama ada secara langsung ataupun tidak langsung. Penglibatan kuasa politik pemerintah dalam tadbir urus institusi zakat di Pulau Pinang dapat dilihat dengan penglibatan ahli-ahli politik ataupun orang yang menjadi penyokong kuat kepada parti politik yang memerintah dalam Ahli Lembaga Pengarah (ALP) ZPP. Selain daripada menasihati dan memberi pandangan berkaitan dengan tadbir urus zakat di Pulau Pinang, mereka juga mempunyai agenda tertentu untuk kepentingan parti masing-masing bagi memenangi hati rakyat. Terdapat dalam kalangan ahli politik pemerintah yang meminta penyaluran bantuan zakat disalurkan melalui mereka dengan tujuan mendapatkan kepercayaan dan keyakinan 
daripada masyarakat terhadap kuasa yang ada pada ahli politik tersebut dan juga kerajaan yang memerintah (Noor: 2016).

Menurut Mohamad Kairi Ghazali (Temu bual bersemuka, 3 Ogos 2016), penglibatan kuasa politik dalam tadbir urus zakat di Pulau Pinang boleh memberi kesan yang baik jika dilaksanakan secara positif dan membina. Namun, jika penglibatan kuasa politik dengan tujuan untuk kepentingan individu dan parti politik, ia akan memberi kesan yang buruk terhadap tadbir urus institusi tersebut. Begitu juga Mohd Noor Harun (Temu bual besemuka, 5 November 2016) menjelaskan bahawa kuasa politik pemerintah memang mempengaruhi dan amat berperanan dalam tadbir urus institusi zakat di Pulau Pinang. Walaupun ZPP ditubuhkan sebagai syarikat Sdn. Bhd., kuasa politik pemerintah mempunyai peranan dalam menentukan dasar dan hala tuju institusi zakat dan juga boleh mempengaruhi keputusan yang dibuat oleh ALP ZPP agar selari dengan polisi dan dasar yang telah ditetapkan oleh kerajaan atau kuasa politik pemerintah (Rahman:2016; Harun: 2016).

Menurut Mohamad Salleh Abdullah (Temu bual bersemuka, 21 Jun 2016) dan Mohamad Kairi Ghazali (Temu bual bersemuka, 3 Ogos 2016), walaupun ZPP diberi kuasa penuh mentadbir urus kutipan dan agihan zakat di Pulau Pinang, namun setiap perancangan dan keputusan yang dibuat pada peringkat ZPP mesti mendapat persetujuan dan kelulusan daripada MAINPP dan juga EXCO Hal Ehwal Agama Islam Pulau Pinang. Hal ini kerana EXCO Hal Ehwal Agama Islam Pulau Pinang dan MAINPP mempunyai kuasa dalam melantik ALP ZPP sama ada melalui mesyuarat EXCO Kerajaan Negeri Pulau Pinang ataupun mesyuarat Ahli MAINPP. Terdapat sebahagian daripada ALP ZPP yang dilantik daripada ahli politik atau penyokong kepada parti politik yang memerintah. Selain itu, MAINPP juga berkuasa untuk menamatkan jawatan seseorang ALP ZPP serta merta walaupun beliau dilantik untuk tempoh masa dua tahun (Kassim: 2016). Pelantikan Ahli MAINPP pula adalah lantikan DYMM Seri Paduka Baginda Yang Di-Pertuan Agong hasil daripada cadangan parti-parti yang mewakili kerajaan yang memerintah (Kassim: 2016; Rahman: 2016).

Selain daripada pelantikan ALP ZPP, kuasa politik pemerintah juga berperanan dalam pelantikan wakil amil bagi mengutip zakat di setiap daerah di Pulau Pinang. Menurut Mohamad Kairi Ghazali (Temu bual bersemuka, 3 Ogos 2016), walaupun ZPP diberi kuasa untuk tadbir urus kutipan zakat di Pulau Pinang, namun ZPP tidak ada kuasa untuk melantik wakil amil di setiap daerah di Pulau Pinang kerana pelantikan amil zakat di Pulau Pinang adalah kuasa MAINPP. ZPP hanya boleh mencadangkan calon wakil amil yang dikenal pasti kepada MAINPP dan pelantikan akan dibuat oleh MAINPP setelah mendapat persetujuan daripada EXCO Hal Ehwal Agama Islam Pulau Pinang (Abdullah: 2016; Ghazali: 2016).

Selain daripada politik, ekonomi juga berperanan dalam memperkasakan tadbir urus zakat di Pulau Pinang. Menurut Mohamad Salleh Abdullah (Temu bual bersemuka, 21 Jun 2016) dan Mohd Noor Harun (Temu bual besemuka, 5 November 2016), peranan dan tanggungjawab ZPP sebagai amil zakat yang dilantik oleh MAINPP adalah mentadbir urus zakat di Pulau Pinang dengan lebih sistematik, cekap dan berkesan bagi meningkatkan kutipan dan agihan zakat di Pulau Pinang. Selain itu, ZPP juga bertanggungjawab untuk memudahkan urusan pembayaran 
dan permohonan zakat bagi memuaskan hati pelanggan yang berurusan dengan ZPP (Noor: 2016).

Mohamad Kairi Ghazali (Temu bual bersemuka, 3 Ogos 2016) menyatakan ZPP telah berjaya membuktikan bahawa penubuhannya sebagai amil zakat kepada MAINPP mampu merealisasikan matlamat yang telah ditetapkan oleh MAINPP. Dalam masa yang sama penubuhan ZPP juga dapat meningkatkan keyakinan masyarakat terhadap tadbir urus institusi zakat di Pulau Pinang. Setelah kuasa dan tanggungjawab untuk menguruskan kutipan dan agihan zakat di Pulau Pinang diberikan sepenuhnya kepada ZPP pada tahun 1999, jumlah kutipan dan pembayar zakat meningkat pada setiap tahun. Begitu juga jumlah agihan zakat telah meningkat dari semasa ke semasa. Peningkatan jumlah kutipan zakat di Pulau Pinang merupakan sumber kekuatan ekonomi ZPP dalam membangunkan masyarakat Islam di Pulau Pinang.

Setelah berjaya meningkatkan kutipan zakat di Pulau Pinang, ZPP mempelbagaikan bentuk agihan dan bantuan zakat kepada golongan asnaf. Selain daripada bantuan sara diri kepada golongan asnaf, ZPP juga memperkenalkan skim bantuan yang bersifat produktif seperti melaksanakan program-program pembangunan ekonomi dan keusahawanan, pendidikan, kemahiran dan kesihatan (Abdullah: 2016). Antara skim bantuan produktif yang diperkenalkan oleh ZPP ialah bantuan modal dan peralatan atau mesin serta Program Gerak Kerja Asnaf. Bantuan modal dan peralatan atau mesin merupakan bantuan modal dengan bajet permulaan sebanyak RM 100,000.00 yang diberikan kepada golongan asnaf yang ingin memulakan perniagaan. Program Gerak Kerja Asnaf pula merupakan program yang berbentuk latihan dan kemahiran yang diajar kepada golongan asnaf untuk meningkatkan ekonomi dan kemahiran masyarakat Islam di Pulau Pinang. Terdapat lima Program Gerak Kerja Asnaf yang telah diperkenalkan oleh ZPP bagi meningkatkan ekonomi dan kemahiran masyarakat Islam di Pulau Pinang. Program tersebut ialah yaitu Gerak Asnaf Niaga, Gerak Asnaf Tani, Gerak Asnaf Jahitan, Gerak Asnaf Katering dan Gerak Asnaf IT.

Selain itu, Program Gerak Asnaf juga dilaksanakan untuk meningkatkan tahap pendidikan dan kesihatan masyarakat Islam di Pulau Pinang (Abdullah: 2011). Bagi meningkatkan tahap pendidikan masyarakat Islam di Pulau Pinang, ZPP menganjurkan program pembangunan akademik dan sahsiah pelajar seperti kelas malam (prep night class), Kem Bina Sahsiah (Smart Caliphs Camp) dan Program Didik Cemerlang Akademik (PDCA). Dalam program pembangunan kesihatan pula, kebanyakan perbelanjaan disalurkan melalui enam buah Pusat Rawatan Haemodalisis Zakat (PHZ) dan juga Klinik Bergerak Zakat (KBZ) (Zakat Pulau Pinang, 2013). Program ekonomi di atas memberi kesan kepada politik institusi zakat itu sendiri yaitu meyakinkan masyarakat terhadap ketelusan tadbir urus kutipan dan agihan zakat di Pulau Pinang (Abdullah: 2016).

Menurut Mohamad Kairi Ghazali (Temu bual bersemuka, 3 Ogos 2016), kejayaan ZPP meningkatkan kutipan zakat dan mempelbagaikan bentuk agihan dan bantuan zakat di Pulau Pinang telah menambah keyakinan masyarakat Islam di Pulau Pinang terhadap tadbir urus institusi zakat di Pulau Pinang. Keadaan sedemikian telah memberi kesan positif kepada peningkatan jumlah kutipan dan agihan 
zakat di Pulau Pinang dari semasa ke semasa. Peningkatan jumlah kutipan dan agihan zakat di Pulau Pinang dari tahun 1994 hingga tahun 2015.

Jumlah kutipan zakat di Pulau Pinang bermula pada tahun 1994 hingga 2015 dan jumlah agihan zakat di Pulau Pinang bermula pada tahun 2006 hingga tahun 2015. Merujuk kepada Jadual 4.2 tersebut, dapat dirumuskan bahawa jumlah kutipan dan agihan zakat di Pulau Pinang meningkat pada setiap tahun. Pada tahun 1994, kutipan zakat di Pulau Pinang hanyalah RM 193,306.00 yang dikutip daripada 212 orang pembayar zakat. Pada tahun 1995 pula, jumlah kutipan dan pembayar zakat di Pulau Pinang semakin meningkat menjadikan jumlah kutipan pada tahun tersebut ialah RM 5,956.693.00 dan jumlah pembayar zakat ialah seramai 4,723 orang. Begitu juga pada tahun 1996, jumlah kutipan zakat di Pulau Pinang meningkat kepada RM 6,554,270.00 yang dibayar oleh 7,911 orang pembayar zakat. Jumlah kutipan dan pembayar zakat di Pulau Pinang terus meningkat pada setiap tahun seterusnya sehinggalah pada tahun 2015 dengan jumlah kutipan sebanyak RM 88,282,057 dan jumlah pembayar zakat adalah seramai 62,977orang. Peningkatan ini bukan sahaja berlaku dari segi kutipan dan pembayar zakat sahaja, malah jumlah agihan zakat dan bilangan asnaf di Pulau Pinang juga meningkat pada setiap tahun.

Peningkatan jumlah agihan zakat di Pulau Pinang bermula dari tahun 2006 hingga 2015. Pada tahun 2006 jumlah agihan zakat di Pulau Pinang ialah RM 26,343,520.00 yang diagihkan kepada 22,049 orang asnaf. Pada tahun 2007 pula, jumlah agihan zakat di Pulau Pinang semakin meningkat kepada RM 34,569,379.00. Jumlah ini telah diagihkan kepada 23,031 orang asnaf pada tahun tersebut. Pada tahun berikutnya yaitu bermula pada tahun 2012 hingga tahun 2015, jumlah agihan zakat di Pulau Pinang meningkat sebanyak RM 31,322,857.00. Jumlah keseluruhan agihan zakat di Pulau Pinang pada tahun 2015 ialah RM 101,374,478.00. Begitu juga jumlah penerima zakat di Pulau Pinang, bilangannya meningkat dari tahun 2012 hingga tahun 2015 yaitu seramai 11,481. Peningkatan jumlah penerima zakat ini menjadikan jumlah keseluruhan penerima zakat di Pulau Pinang pada tahun 2015 ialah 45,228 orang.

\section{Hubungan Ekonomi dengan Politik dalam Institusi Zakat di Pulau Pinang}

Seperti yang dinyatakan sebelum ini, Institusi zakat merupakan sebuah institusi yang dilantik oleh pemerintah untuk menguruskan ekonomi umat Islam berkaitan kutipan dan agihan zakat. Lantaran itu, sudah semestinya institusi tersebut terikat dengan dasar dan polisi kuasa politik pemerintah dalam pengurusan dan pentadbirannya. Menurut Muhammad Syukri Salleh (2016), institusi zakat tidak boleh berfungsi dengan sendiri tanpa campur tangan kuasa politik sama ada pada peringkat negara, negeri, penguasa agama ataupun institusi zakat itu sendiri. Begitu juga dengan institusi zakat di Pulau Pinang, terdapat hubungan yang saling mempengaruhi antara kuasa politik pemerintah dengan ekonomi dalam memperkasakan pengurusan dan pentadbirannya.

Menurut Y.B. Dato' Abdul Malik Kassim (Temu bual bersemuka, 20 Oktober 2016), Mohamad Kairi Ghazali (Temu bual bersemuka, 3 Ogos 2016) dan Mohd Noor Harun (Temu bual besemuka, 5 November 2016), dalam konteks tadbir urus zakat di Pulau Pinang, ekonomi dan kuasa politik pemerintah saling berkait antara satu sama 
lain. Mereka menyatakan bahawa zakat merupakan sesuatu yang penting kepada ahli politik pemerintah khususnya kepada wakil rakyat yang dilantik. Begitu juga sebaliknya, pentingnya ahli politik atau wakil rakyat kepada zakat bagi merealisasikan matlamat dan tujuannya. Sebagai contoh, sekiranya terdapat rakyat yang ditimpa musibah pada waktu-waktu tertentu seperti rumah terbakar atau ditimpa kemalangan pada waktu tengah malam, wakil rakyat merupakan orang yang bertanggungjawab untuk menghulurkan bantuan dan menyelesaikan masalah yang dihadapi mangsa tersebut berbanding dengan pegawai zakat yang dilantik (Kassim: 2016). Menurut beliau lagi, wakil rakyat adalah wakil kepada rakyat. Mereka sentiasa bersama rakyat, manakala pegawai-pegawai zakat tidak semestinya sentiasa berada bersama rakyat. Pegawaipegawai zakat adalah mereka yang bekerja makan gaji dan tugas mereka adalah terhad dan terbatas mengikut masa, peraturan dan prosedur kerja mereka, sedangkan wakil rakyat adalah orang yang bekerja dan berkhidmat selama 24 jam sehari untuk menjaga kebajikan rakyat.

Selain itu, zakat juga merupakan satu kaedah bantuan bagi mengatasi masalah kemiskinan masyarakat Islam. Namun, bagi mencapai matlamat tersebut, ia memerlukan kepada kuasa politik pemerintah agar pengagihannya lebih adil dan berkesan. Menurut Dato' IR. Ahmad Zakiyuddin Abd Rahman (Temu bual bersemuka, 3 November 2016), pembasmian kemiskinan merupakan tanggungjawab utama kerajaan yang memerintah. Selain daripada peruntukan kewangan yang diperuntukkan dalam anggaran perbelanjaan Kerajaan Negeri Pulau Pinang pada setiap tahun, kerajaan yang memerintah juga boleh menggunakan zakat sebagai salah satu kaedah pembasmian kemiskinan untuk membangunkan ekonomi masyarakat Islam di Pulau Pinang.

Menurut Wan Salim Wan Mohd Noor (Temu bual bersemuka, 27 Jun 2016), zakat merupakan salah satu mekanisme yang boleh digunakan untuk membantu dan menyelesaikan masalah yang dihadapi oleh masyarakat Islam. Namun, bagi mencapai matlamat tersebut, ia memerlukan kepada tadbir urus yang cekap dan profesional dan selari dengan tuntutan Islam. Senada dengan itu, Dato' IR. Ahmad Zakiyuddin Abd Rahman (Temu bual bersemuka, 3 November 2016) juga menjelaskan bahawa zakat merupakan salah satu daripada rukun Islam yang difardhukan kepada golongan yang kaya untuk membantu golongan miskin dan perlu diuruskan secara adil oleh pemerintah ataupun pihak yang bertanggungjawab. Oleh itu, mana-mana kerajaan atau kuasa politik pemerintah boleh menggunakan zakat untuk membantu menyelesaikan masalah ekonomi golongan tersebut, namun mesti meletakkan tadbir urus zakat adalah untuk memartabatkan agama Islam dan agenda Islam mesti diutamakan daripada kepentingan atau matlamat parti yang memerintah.

Sememangnya tidak dapat dinafikan bahawa ekonomi dan politik saling memerlukan antara satu sama lain dalam memperkasakan tadbir urus institusi zakat di Pulau Pinang. Menjadi tanggungjawab kerajaan atau kuasa politik pemerintah untuk memastikan dasar dan polisi institusi tersebut agar selari dengan dasar dan polisi kerajaan yang memerintah (Ghazali: 2016). Menurut Y.B. Dato' Abdul Malik Kassim (Temu bual bersemuka, 20 Oktober 2016), menjadi tanggungjawab kerajaan atau kuasa politik pemerintah untuk mengawasi setiap perkara yang berlaku di Pulau Pinang 
sama ada dari segi pembangunan, ekonomi, kebajikan, sosial dan perkara-perkara yang berkaitan dengan hal ehwal agama Islam. Begitu juga apa yang dinyatakan oleh Dato' IR. Ahmad Zakiyuddin Abd Rahman (Temu bual bersemuka, 3 November 2016) mengenai hubungan ekonomi dengan politik dalam institusi zakat di Pulau Pinang. Beliau menyatakan bahawa Kerajaan Negeri Pulau Pinang bertanggungtawab dalam menentukan hala tuju pengurusan dan pentadbiran MAINPP dan ZPP bagi memastikan polisi kerajaan negeri bekaitan hal ehwal agama Islam dan tadbir urus kutipan dan agihan zakat di Pulau Pinang tercapai. Contohnya, dalam pengagihan bantuan zakat di Pulau Pinang, terdapat kriteria-kriteria yang tertentu yang perlu dipatuhi oleh MAINPP dan ZPP dalam menentukan bentuk agihan zakat dan golongan asnaf zakat agar selari dengan dasar kerajaan yang memerintah. Oleh itu, kuasa politik pemerintah bertanggungjawab bagi memastikan ZPP tidak melakukan perkara-perkara yang bertentangan dengan polisi dan dasar kerajaan yang memerintah.

Menurut Wan Salim Wan Mohd Noor (Temu bual bersemuka, 27 Jun 2016) dan Y.B. Dato' Abdul Malik Kassim (Temu bual bersemuka, 20 Oktober 2016), urusan hal ehwal agama Islam dan tadbir urus zakat di Pulau Pinang adalah di bawah bidang kuasa EXCO Hal Ehwal Agama Islam Pulau Pinang dan MAINPP sebagai pentadbir dan pihak yang berkuasa. EXCO Hal Ehwal Agama Islam Pulau Pinang dan MAINPP bertanggungjawab untuk mengawasi setiap perkara yang berkaitan dengan hal ehwal agama Islam dan zakat di Pulau Pinang memandangkan kerajaan Negeri Pulau Pinang adalah diketuai oleh golongan bulan Islam (Noor: 2016).

Y.B. Dato' Abdul Malik Kassim (Temu bual bersemuka, 20 Oktober 2016) mengatakan bahawa EXCO Hal Ehwal Agama Islam Pulau Pinang mempunyai tanggungjawab kepada Dewan Undang Negeri Pulau Pinang (DUN). Sekiranya dipersoalkan dalam mesyuarat DUN Pulau Pinang berkaitan hal ehwal agama Islam dan tadbir urus zakat di Pulau Pinang, EXCO Hal Ehwal Agama Islam Pulau Pinang bertanggungjawab untuk memberi penerangan dan jawapan. Oleh yang demikian, MAINPP dan ZPP perlu melaporkan semua aktiviti yang dilaksanakan dari semasa ke semasa kepada EXCO Hal Ehwal Agama Islam Pulau Pinang. MAINPP dan ZPP juga perlu mendapat persetujuan dan kelulusan daripada EXCO Hal Ehwal Agama Islam Pulau Pinang dalam melaksanakan sesuatu dasar atau polisi baharu berkaitan kutipan dan agihan zakat di Pulau Pinang. Begitu juga pelantikan ALP ZPP dan amil zakat di Pulau Pinang, ZPP perlu mendapatkan persetujuan dan kelulusan daripada EXCO Hal Ehwal Agama Islam Pulau Pinang walaupun telah disepakati dalam mesyuarat ALP ZPP.

Selain daripada itu, Y.B. Dato' Abdul Malik Kassim (Temu bual bersemuka, 20 Oktober 2016) juga menyatakan bahawa EXCO Hal Ehwal Agama Islam Pulau Pinang mempunyai kuasa untuk melaksanakan sesuatu perkara secara terus tanpa pengetahuan pihak MAINPP atau ALP ZPP sekiranya terdapat isu-isu yang berkaitan dengan tadbir urus zakat di Pulau Pinang. Misalnya, EXCO Hal Ehwal Agama Islam Pulau Pinang berhak mengarahkan jabatan audit luar untuk melakukan audit terhadap tadbir urus zakat di Pulau Pinang tanpa minta persetujuan dan kebenaran daripada MAINPP dan ALP ZPP. 


\section{KESIMPULAN DAN IMPLIKASI}

Berdasarkan penelitian dan hasil temu bual dengan tujuh orang responden berkaitan ekonomi politik institusi zakat di Pulau Pinang, dapat dirumuskan bahawa strategi utama penubuhan ZPP sebagai institusi swasta untuk mentadbir urus kutipan dan agihan zakat di Pulau Pinang adalah untuk mengukuhkan ekonomi dan politik institusi zakat di Pulau Pinang. Dari sudut ekonomi, penubuhan ZPP adalah untuk meningkatkan kutipan dan agihan zakat di Pulau Pinang, manakala dari sudut politik pula, ia bertujuan menjadikan pengurusan zakat di Pulau Pinang lebih tersusun, sistematik dan profesional di samping meningkatkan keyakinan masyarakat Islam di Pulau Pinang terhadap pengurusan dan pentadbiran zakat di Pulau Pinang walaupun pentadbiran kerajaan negeri Pulau Pinang diketuai oleh golongan bukan Islam. Keyakinan masyarakat terhadap institusi zakat penting dalam memastikan peranan sebenar institusi zakat ditubuhkan dapat dilaksanakan dengan jayanya yaitu meningkatkan jumlah kutipan dan pembayar zakat di Pulau Pinang serta membangunkan masyarakat Islam di Pulau Pinang.

Sememangnya tidak dapat dinafikan bahawa ekonomi dan politik dalam institusi zakat di Pulau Pinang saling berkait dan saling memerlukan antara satu sama lain. Ekonomi politik institusi zakat di Pulau Pinang berperanan dalam memastikan setiap dasar dan pelaksanaan pada peringkat institusi zakat di Pulau Pinang dapat direalisasikan dan selari dengan dasar dan polisi Kerajaan Negeri Pulau Pinang. Selain itu, ekonomi politik institusi zakat di Pulau Pinang juga memainkan peranan dalam menjadikan tadbir urus institusi zakat di Pulau Pinang lebih sistematik dan profesional serta diyakini oleh masyarakat. Walaupun terdapat dakwaan yang mengatakan penglibatan ahli politik dalam tadbir urus institusi zakat di Pulau Pinang mempunyai agenda tertentu untuk memenangi hati rakyat bagi kepentingan parti masing-masing. Namun, pada hakikatnya menjadi tanggungjawab ahli politik atau wakil rakyat yang dipilih oleh rakyat dan dilantik oleh kerajaan yang memerintah untuk memastikan tadbir urus zakat di Pulau Pinang menjadi lebih agresif dan progresif.

\section{DAFTAR PUSTAKA}

Abdullah, Mohammad Salleh. 2011. Realiti Agihan Zakat di Pulau Pinang: Saradiri atau produktif? Dlm. Muhammad Syukri Salleh, Mohammad Salleh Abdullah \& Zahri Hamat (Ed.), Tranformasi zakat: Dari zakat saradiri kepada zakat produktif (pp.251-285). Pulau Pinang: Katarsis Enterprise @ Printa Printing Sdn. Bhd.

Ahmad, Sanep, Hairunnizam Wahid dan Adnan Mohamad. 2006. Penswastaan Institusi Zakat Dan Kesannya Terhadap Pembayaran Secara Formal. International Journal of Management Studies 13:2: 175-195.

Ahmad, Shofian dan Luqman Mahadi. 2013. Pelaburan Wang Zakat Oleh Institusi Zakat Menurut Pandangan Islam. Jurnal Kanun DBP. Jil. 10, Bil. 4: 122135.

Bakar, Mohamad Zaini Abu. 2011. PrinsipPrinsip Tadbir Urus Dalam Transformasi Institusi Zakat. Dlm. Muhammad Syukri Salleh, Mohammad Salleh Abdullah \& Zahri Hamat (Ed.), Tranformasi zakat: Dari zakat saradiri kepada zakat produktif (pp.285-294). Pulau Pinang: Katarsis 
Enterprise @ Printa Printing Sdn. Bhd.

Hassan, Nik Mustapha Nik. 2001. Kaedah

Pengagihan Dana Zakat: Satu

Perspektif Islam. Kuala Lumpur: IKIM.

Hussain, Md Hairi Md. 1999. Keberkesanan

Sistem Agihan Zakat: Suatu

Pandangan Awal. Laporan Kajian.

Fakulti Perakaunan. Universiti Utara Malaysia.

Hussain, Md Hairi Md, Kamil Md. Idris dan Ram Al-Jaffri Saad. 2012. Ketelusan Di Dalam Tadbir Urus Institusi Zakat. Prosiding Seminar Isi-isu Kontemporari Zakat di Malaysia yang dibentangkan di My Hotel, Bandar Kuah, Langkawi pada 22-25 November 2012.

Ibrahim, Patmawati Hj. 2008. Pembangunan Ekonomi Melalui Agihan Zakat: Tinjauan Empirical. Jurnal Syariah, Jil. 16, Bil. 2: 223-244

JAWHAR. 2010. Pusat pungutuan zakat di Malaysia. Diakses daripada http://www.jawhar.gov.my/pusatpungutan-zakat/ pada 10 Disember 2015.

Kader, Radiah Abdul, Hairunnizam Wahid dan Sanep Ahmad. 2010. Cadangan Melokalisasikan Pengagihan Zakat: Persepsi Terhadap Amil Dan Penerima Zakat. Kajian rintis Penyelidikan di bawah geran UKMGup-JKKBG-08-03-2009.

MAIWP. 2006. Laporan Tahunan MAIWP 2006. Diakses daripada http://www.maiwp.gov. my/i/index.php/perkhidmatankami/muatturun/category/23laporan-tahunan pada 20 Oktober 2015.

Roketkini.com. 2015. Walaupun Tiada Lagi Kerajaan Pakatan Rakyat di Pulau Pinang, Pentadbiran CAT diteruskan dengan Sokongan PKR dan Wakil Tunggal PAS. Diakses daripada http://www.roketkini.com/2015/07/ 02/walaupun-tiada-lagi-kerajaanpakatan-rakyat-di-pulau-pinangpentadbiran-cat-diteruskan-dengansokongan-pkr-dan-wakil-tunggalpas/pada 20 Ogos 2016.

Rosdi, Mohd Syakir Mohd. 2010. Dr. Burhanuddin Al-Helmi dan Pembangunan Ekonomi Politik Islam di Malaysia. Disertasi. Pusat Pengajian Sains Kemasyarakatan (Pengurusan Pembangunan Islam), Universiti Sains Malaysia.

Rosdi, Mohd Syakir Mohd. 2012. Erti Ekonomi Politik Islam. Artikel yang dibentangkan di Bengkel Reseach University Team (RUT), bertempat di C06, Pusat Pengajian Sains Kemasyarakatan, USM, anjuran Pusat Kajian Pengurusan Pembangunan Islam (ISDEV) pada 23-24 Mei 2012.

Rosdi, Mohd Syakir Mohd. 2014. Ekonomi Politik Islam: Teori dan Falsafah. Kuala Lumpur: Dewan Bahasa dan Pustaka.

Sulong, Jasni dan Anwar Mohd Ali. 2012. Kajian Perbandingan dalam Pentadbiran Undang-Undang Kutipan Zakat di Provinsi Aceh dan Negeri Kedah. Jurnal Kajian Malaysia. Volume 30 No. 1: 107-138.

Tarimin, Mujaini. 2006. Zakat Menuju Pengurusan Profesional. Kuala Lumpur: Utusan Publication \& Distrubutions Sdn. Bhd.

Zakat Pulau Pinang. 2013. Maklumat Korporat dan Sejarah Penubuhan ZPP. Diakses daripada http://www.zakatpenang.com/zpp/i ndex.php/info-zpp/maklumatkorporat pada 20 Disember 2015. 


\section{Ucapan Terima Kasih}

Dewan Redaksi serta Redaksi Pelaksana Jurnal Syarikah mengucapkan terima kasih dan penghargaan setinggi-tingginya kepada para pakar yang telah berperan sebagai mitra bebestari pada penerbitan Jurnal Syarikah Volume 3 Nomor 1 Juni Tahun 2017.

$$
\text { Dr. Nurul Huda, M.Si }
$$

Semoga kerjasama yang baik dapat terus berlangsung di masa-masa yang akan datang untuk lebih meningkatkan kualitas Jurnal Syarikah. 


\title{
PANDUAN BAGI PENULIS JURNAL SYARIKAH: JURNAL EKONOMI ISLAM
}

\author{
Pemutakhiran Juni 2017
}

\section{RUANG LINGKUP}

Jurnal Syarikah: Jurnal Ekonomi Islam mendorong pengembangkan ilmu pengetahuan dan teknologi dalam bidang Ekonomi Islam melalui penerbitan karya ilmiah berbasis hasil penelitian (orisinal).

\section{JENIS NASKAH}

Jenis naskah yang dipublikasikan adalah naskah orisinal hasil penelitian yang belum pernah dipublikasikan atau tidak sedang dalam proses publikasi oleh media publikasi lain dan terbebas dari plagiarisme. Bahasa publikasi adalah bahasa Indonesia atau bahasa Inggris. Setiap naskah yang masuk ke dewan redaksi akan menjalani proses peer-review.

Naskah hasil penelitian harus didasarkan atas data hasil penelitian orisinal yang belum dipublikasikan dan dianalisis menggunakan metode statistik. Naskah hasil penelitian yang disajikan secara deskriptif tanpa rancangan penelitian yang dikontrol oleh peneliti, naskah hasil penelitian yang hanya berupa pengulangan (replikasi) dari hasil penelitian yang telah dipublikasikan, misalnya hanya kondisi geografisnya yang berbeda, tidak akan dipertimbangkan untuk dipublikasikan. Naskah bernomor seri tidak dapat diterima, kecuali disampaikan dan disajikan pada waktu yang bersamaan.

\section{PENGIRIMAN NASKAH}

Naskah yang diajukan ditujukan ke Pimpinan Dewan Redaksi Jurnal Syarikah, melalui e-mail ke tuti.kurnia@unida.ac.id. Naskah dimaksud harus dilengkapi dengan Surat Pernyataan Orisinalitas dan Pemindahan Hak Publikasi yang ditandatangi oleh semua penulis.

\section{KONVENSI DAN KETAATASASAN}

Naskah harus ditulis dengan tema font Time New Roman 12, spasi ganda, batas tepi $2,5 \mathrm{~cm}$, halaman berukuran A4, menggunakan program microsoft office word. Naskah ditulis tidak lebih dari 7.500 kata berdasarkan urutan bagian berikut:

1) Judul (Title): JUDUL berbahasa Indonesia dan Inggris, Nama Penulis, Alamat Penulis, Penulis untuk Korespondensi, dan Judul Singkat (Running Head).

2) Tajuk Utama (main section headings): ABSTRACT, ABSTRAK, PENDAHULUAN, MATERI DAN METODE, HASIL, PEMBAHASAN, KESIMPULAN DAN IMPLIKASI, UCAPAN TERIMA KASIH, DAFTAR PUSTAKA.

3) Lampiran: Tabel, Grafik, dan Gambar.
Judul naskah harus berhuruf tebal dan kapital, ditulis pada bagian tengah dari baris tersendiri. Tajuk dan subtajuk ditulis pada baris tersendiri, mulai dari batas tepi kiri badan teks. Tajuk berhuruf tebal dan kapital. Subtajuk berhuruf tebal dan huruf kapitalnya hanya pada awal kata. Jarak antara tajuk dan subtajuk adalah 10 point (pt) sedangkan jarak antara tajuk atau subtajuk dan badan teks adalah 6 pt. Pembeda paragraf dimulai pada paragraf kedua setelah tajuk atau subtajuk dan dicirikan oleh baris pertamanya yang berjarak $0,5 \mathrm{~cm}$ dari batas tepi kiri badan teks.

Naskah yang terlalu panjang atau terlalu pendek akan dikembalikan kepada penulis. Sebagai pedoman, 7.500 kata setara dengan 34 halaman ukuran A4, yang ditulis dengan tema font Time New Roman 12, spasi ganda, marjin $2,5 \mathrm{~cm}$ dari semua tepi halaman. Judul tidak lebih dari 12 kata, Judul Singkat tidak lebih dari 50 karakter, Abstract dan Abstrak masing-masing tidak lebih dari 250 kata, key words dan kata kunci masing-masing 5 kata, dan Pendahuluan tidak lebih dari 500 kata.

\section{Judul}

Judul harus ringkas dan padat informasi, tidak memuat kata singkatan, dan memuat hal-hal berikut:

a) membangkitkan minat bagi pembaca yang memindai jurnal atau daftar judul jurnal.

b) Menyediakan informasi yang cukup bagi pembaca untuk menilai relevansi suatu naskah dengan minatnya

c) Memasukkan kata kunci atau frasa yang dapat digunakan dalam mengindeks dan menarik informasi tentang penelitian yang dilakukan.

d) Menghindari kata-kata yang tidak penting, seperti "suatu studi kasus ...." atau "suatu tinjauan empiris tentang ....". Hal-hal tersebut lebih tepat ditulis pada subbagian Materi dan Metode.

e) Tidak boleh memuat kata tempat, seperti “.... di Bogor"

\section{Nama dan Alamat Penulis}

Nama dan alamat penulis harus disajikan seperti contoh berikut:

G. PraditinKa ${ }^{1, a}$ dan W. munawar ${ }^{2}$

${ }^{1}$ Lembaga Penelitian dan Pengembangan Universitas Djuanda, Jl. Tol Ciawi Kotak Pos 35 Bogor 16720.

${ }^{2}$ Program Studi Ekonomi Islam Fakultas Ekonomi Islam Universitas Djuanda, Jl. Tol Ciawi No. 1 Kotak Pos 35 Bogor 16720.

aKorespondensi: Tuti Kurnia. Telepon: 0818106472; E-mail: tuti.kurnia@unida.ac.id 


\section{Judul Singkat (running head)}

Penulis harus menuliskan judul singkat tidak lebih dari 50 karakter termasuk ketukan kosong.

\section{Abstract dan Abstrak}

Abstract ditulis dalam bahasa Inggris baku secara konsisten (American English atau British English). Abstrak ditulis dalam bahasa Indonesia yang baik dan benar, menggunakan kata-kata baku. Baik abstract maupun abstrak dibuat dalam satu paragraf utuh tanpa ada acuan pustaka atau perujuk tabel dan/atau gambar, tidak lebih dari 250 kata. Isinya harus memuat masalah penting yang akan dipecahkan, tujuan, metode, hasil, kesimpulan, dan tidak boleh terlalu padat dengan angka-angka. Penyingkatan kata tidak diperkenankan kecuali kata dimaksud akan digunakan lebih dari satu kali..

\section{Keywords dan Kata Kunci}

Keywords (berbahasa Ingris) dan Kata kunci (berbahasa Indonesia), masing-masing tidak lebih dari lima kata dan sebaiknya tidak sama dengan kata-kata yang terdapat dalam judul naskah. Jika tidak memadai, dewan redaksi akan mengubahnya atas persetujuan penulis.

\section{Pendahuluan}

Pendahuluan yang ditulis tidak lebih dari 500 kata, harus menjelaskan isu-isu mutakhir yang mengarah pada pentingnya penelitian yang dilakukan, tujuan penelitian dinyatakan dengan jelas, dan menuliskan state of the art dari topik penelitiannya sehingga gambaran utama penelitiannya menjadi jelas bagi para pembaca. Namun, acuan pustaka dalam pendahuluan harus dibatasi karena bukan merupakan pembahasan awal.

\section{Materi dan Metode}

Materi dan metode penelitian harus dijelaskan secara terperinci pada bagian ini sehingga memungkinkan bagi peneliti lain untuk mengulang penelitian ini. Materi atau bahan yang digunakan tidak diperinci secara terpisah, melainkan harus terintegrasi dengan prosedur penelitian. Misalnya, .."responden diminta mengisi daftar pertanyaan menggunakan pensil 2B dan memilih satu dari tiga poster yang diperlihatkan oleh peneliti...", tidak perlu memerincinya seperti berikut: " Materi penelitian terdiri atas: daftar pertanyaan, pensil 2B, dan poster. Jika penelitian menggunakan produk berpemilik (seperti paten) untuk pembanding, produk dimaksud harus dituliskan dalam nama yang baku atau dituliskan merk dagangnya di dalam tanda kurung jika dianggap membantu memperjelas pemahaman pembaca, namun syaratnya harus mendapat izin tertulis dari pemilik produk dimaksud sebelum dipublikasikan. Model, tipe, merk, dan produsen peralatan yang digunakan dalam penelitian harus dijelaskan. Metode dan model analisis statistik harus jelas sehingga memungkinkan bagi peneliti lain untuk melakukan pengulangan.

Sistematika penulisannya diurutkan sebagai berikut: materi, rancangan percobaan dan perlakuan, prosedur pelaksanaan penelitian, analisis laboratorium, dan analisis statistik. Sistematika ini tidak kaku, dapat disesuaikan dengan ciri bidang keilmuan. Misalnya, untuk penelitian agribisnis yang tidak ada analisis laboratoriumnya, tidak perlu ada analisis laboratorium. Sebaliknya, subbagian lainnya dapat ditambahkan sesuai kebutuhan.

\section{Hasil dan Pembahasan}

Hasil penelitian, termasuk hasil analisis statistiknya dipaparkan secara terperinci dalam bagian ini. Ilustrasi, jika diperlukan dapat disajikan dalam bentuk tabel dan/atau gambar. Tabel dan gambar harus sederhana, informatif, mudah dipahami, dan mandiri, dalam arti tabel atau gambar dimaksud harus bisa menjelaskan kepada pembaca sehingga pembaca tidak harus membaca tulisannya untuk memahaminya. Hal yang sudah dijelaskan dalam tabel atau gambar tidak perlu diulang dalam tulisan. Tabel dan gambar dimuat pada halaman terpisah darik teks.

Hasil penelitian selanjutnya dibahas dengan cara membandingkannya dengan hasil penelitian pada topik serupa dari peneliti sebelumnya untuk mengungkap keajegannya (konsistensinya) apakah konsisten (sama) atau berbeda, lalu jelaskan alasan ilmiahnya atas hasil dimaksud secara lugas dan tuntas sehingga memperjelas posisi hasil penelitiannya. Selanjutnya, temuan hasil penelitian diungkapkan disertai kelebihan dan kelemahannya, jika ada. Ungkapan temuan hasil penelitian ini akan mempermudah dalam menyimpulkan hasil penelitian.

Data rataan perlakuan harus ditulis dengan galat bakunya (standard errors). Tingkat signifikansi statistik dapat dinyatakan dalam $\mathrm{P}<0,05, \mathrm{P}<0,01$, dan $\mathrm{P}<0,001$. Khusus pada tabel, tingkat signifikansi dimaksud, berturut-turut dapat ditulis dengan *, **, dan ${ }^{* * *}$ sedangkan pada tabel dan grafik, perbedaan antarperlakuan dapat ditunjukkan dengan huruf $a, b$ untuk $\mathrm{P}<0,05$ dan $\mathrm{A}$, B untuk $\mathrm{P}<0,01$.

\section{Kesimpulan dan Implikasi}

Kesimpulan memuat temuan hasil penelitian yang mencerminkan kebaruan, keorisinilan, kepioneran, keuniversalan, dan kontribusi ilmiah dalam pengembangan ilmu pengetahuan dan teknologi. Pernyataan dalam simpulan terbebas dari frasa atau istilah statistik, seperti " ..berpengaruh nyata $(\mathrm{P}<0,05) "$

Penulis harus menjelaskan implikasi hasil penelitiannya dalam pengembangan keilmuan, dan dampaknya terhadap lingkungan, sosial, budaya, 
ekonomi, politik, dan/atau hukum. Implikasi dipaparkan dalam bahasa yang sederhana agar pembaca noncendekia dapat memahaminya dengan mudah.

\section{Ucapan Terima Kasih}

Ucapan terima kasih hanya wajib ditulis jika penelitian didukung (biaya, sarana, tenaga) oleh instansi atau individu, atau penelaah sejawat jika naskahnya ditelaah sebelum dipublikasikan.

\section{Daftar Pustaka}

Penulis bertanggung jawab atas kebenaran semua sumber pustaka yang dirujuk dan dituliskan dalam Daftar Pustaka dan yang diacu dalam teks. Sumber pustaka sangat dianjurkan menggunakan terbitan terbaru (10 tahun terakhir), dan disajikan secara alfabet dan dituliskan menurut format nama tahun. Beberapa format dan contoh penulisannya antara lain:

Naskah jurnal atau abstrak. Format: Nama Penulis. Tahun. Judul. Nama Jurnal. Volume: Halaman. Contoh:

Rahmawati R, G Praditina dan RA Munjin. 2009. Model pelayanan rumah sakit berbasis karakteristik sosial ekonomi masyarakat untuk meningkatkan kepuasan pasien. Jurnal Humaniora. 1(1): 18-29.

Buku. Format: Nama Penulis atau Nama Editor atau Nama Lembaga. Tahun. Judul. Edisi, Nama Penerbit, Tempat Penerbitan. Contoh:

Roestamy M. 2011. Konsep-konsep hukum kepemilikan properti bagi asing (dihubungkan dengan hukum pertanahan). Edisi pertama. PT. Alumni. Bandung.

Bab buku atau proseding. Format: Nama Penulis. Tahun. Judul. Dalam: Judul buku atau proseding (Nama Editor). Volume: Halaman. Nama Penerbit, Tempat Penerbitan. Contoh:

Goulet D. 2000. Ethics, culture and development: livestock, poverty and quality of rural life. In: Livestock, ethics and quality of life (eds. Hodges, John and Han, In K). 131-154. CABI Publishing, New York, NY 10016, USA.

Laporan pada pertemuan ilmiah (konferensi, workshop, dll) yang tidak tercakup dalam buku atau proseding. Format: Nama Penulis. Tahun. Judul. Judul atau Nama Pertemuan Ilmiah, Tempat Pertemuan. Jumlah halaman. Contoh:

Jalal F. 2011. Tantangan dan peluang pendidikan di Indonesia. Orasi Ilmiah. Wisuda XXVI Sarjana dan Pascasarjana Universitas Djuanda, Bogor. 16 hal.

Tesis atau Disertasi. Format: Nama Penulis. Tahun. Judul. Tesis atau Disertasi. Nama Perguruan Tinggi, Tempat Perguruan Tinggi. Contoh:

Roestamy M. 2008. Kepastian hukum atas kepemilikan rumah dan bangunan gedung oleh investor asing dikaitkan dengan asas nasionalitas dalam sistem hukum pertanahan Indonesia. Disertasi. Program Studi Doktor Ilmu Hukum Fakultas Hukum Universitas Padjadjaran, Bandung.

Karya Ilmiah Lepas yang dimuat pada Website. Karya ilmiah lepas yang dimuat pada website hanya dapat digunakan jika literatur standard lainnya tidak tersedia. Format: Nama Penulis. Tahun. Judul. Diunduh tanggal-bulan-tahun dari http://.... Contoh:

Bryant P. 1999. Biodiversity and Conservation. Retrieved October 4, 1999 from http://darwin bio.uci.edu/ sustain/bio65/Titlpage.htm

\section{Penulisan Nama Penulis yang Diacu pada Teks}

Nama penulis yang diacu di dalam teks tidak diperkenankan menggunakan footnote. Jika jumlah penulis kurang dari tiga nama penulis ditulis semua, jika jumlah penulis tidak kurang dari tiga, hanya penulis utama yang ditulis dan diikuti dengan et al. Contoh: Syamsah (2010) menyimpulkan bahwa pajak dan zakat memiliki hubungan reduktif dan deduktabel. Parameter kualitas layanan puskesmas secara simultan mempengaruhi kepuasan pasien (Yuningsih dan Maulana 2010). Kekurangan dari kualitas pelayanan rumah sakit dapat diatasi apabila rumah sakit memperhatikan karakteristik pasien (Rahmawati et al. 2010). Tingkat kepuasan pasien menjadi indikator penting dalam mengukur kualitas pelayanan kesehatan (Yuningsih dan Maulana 2010; Rahmawati et al. 2010).

\section{Tabel}

Tabel harus dibuat sesederhana dan sesedikit mungkin, namun sekurang-kurangnya harus memuat dua baris data. Jika hanya ada satu baris data, maka penyajiannya harus menggunakan grafik. Garis horisontal tabel hanya boleh untuk mencirikan batas baris teratas (heading) dan garis terbawah dari badan tabel, sedangkan garis-garis kolom tabel tidak diperkenankan. Tabel dibuat dengan menggunakan fungsi tabel dalam program microsoft office word. Judul tabel harus ringkas, jelas, dan informatif, diberi nomor urut angka arab, huruf kapital hanya pada huruf pertama judul tabel kecuali beberapa nama diri, dan ditempatkan di atas badan tabel. Lazimnya, peubah disajikan dalam baris dan perlakuan disajikan pada kolom tabel. Keterangan tabel disajikan di bagian bawah badan tabel tanpa menuliskan kata keterangan. Di dalam teks, nomor tabel harus dirujuk, misalnya: kepribadian dalam pandangan Islam merupakan integrasi sistem kalbu, akal, dan nafsu (Tabel 1). Judul tabel, tabel dan keterangan tabel disajikan pada halaman tersendiri setelah Daftar Pustaka. Lebar tabel $80 \mathrm{~mm}$ atau $160 \mathrm{~mm}$. Jangan menyisipkan tabel pada bagian teks. Contoh Tabel lebar $80 \mathrm{~mm}$ : 
Table 1 Persentase distribusi daya fitrah nafsani dalam pembentukan kepribadian

\begin{tabular}{lccc}
\hline \multirow{2}{*}{$\begin{array}{l}\text { Daya fitrah } \\
\text { nafsani }\end{array}$} & \multicolumn{3}{c}{ Tingkat kepribadian (\%) } \\
\cline { 2 - 4 } & Muthmainnah & Lawwamah & Ammarah \\
\hline Kalbu & 55 & 30 & 15 \\
Akal & 30 & 40 & 30 \\
Nafsu & 15 & 30 & 55 \\
\hline
\end{tabular}

Format tabel diubahsuai dari Sulaiman H (2010) tanpa mengubah substansi.

\section{Gambar dan Grafik}

Gambar dan grafik dibuat dalam format JPEG dan hanya diperbolehkan jika data hasil penelitian tidak dapat disajikan dalam bentuk tabel. Grafik yang dibuat dengan program microsoft office excel harus diubahsuiakan menjadi format JPEG dengan kualitas gambar yang layak cetak. Ukuran lebar gambar adalah $80 \mathrm{~mm}$ atau $160 \mathrm{~mm}$. Judul gambar harus ringkas, jelas, dan informatif, diberi nomor urut angka arab, huruf kapital hanya pada huruf pertama judul gambar kecuali beberapa nama diri, dan ditempatkan di bagian bawah gambar. Contoh gambar berformat JPEG lebar $80 \mathrm{~mm}$ (Gambar 1).

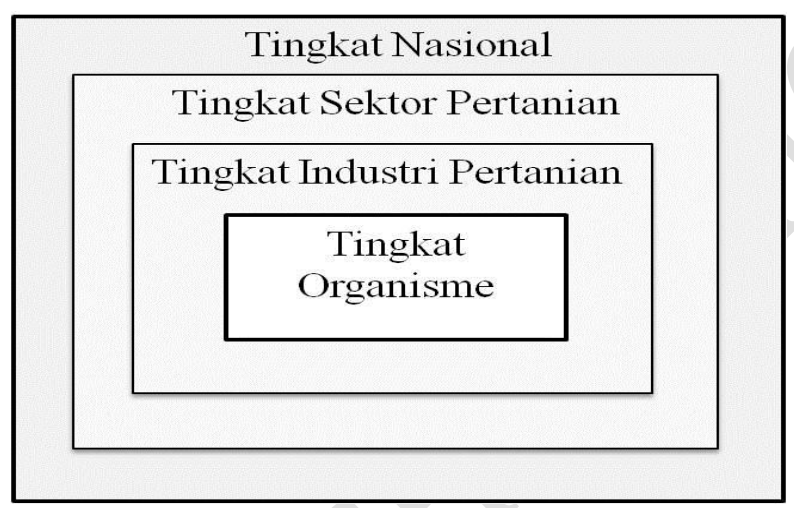

Gambar 1 Empat tingkat domain untuk menghadapi agroterorisme (ubahsuai dari Kohnen 2000).
Keterangan gambar ditulis setelah dan merupakan bagian integral dari judul gambar. Gambar dan judul gambar disajikan pada halaman tersendiri setelah halaman tabel. Di dalam teks, seluruh nomor gambar harus dirujuk secara berurutan seperti nomor tabel. Gambar dicetak hitam putih dan jika penulis menghendaki gambar berwarna, maka biaya pencetakan menjadi tanggung jawab penulis.

\section{Cetak Lepas}

Penulis yang naskahnya telah dipublikasikan akan mendapatkan satu Jurnal Humaniora dan dua eksemplar cetak lepas (reprint) artikelnya. Penulis yang ingin menambah jumlah jurnal dan cetak lepasnya dapat memesannya ke Dewan Redaksi melalui telefon atau email. Berikut ini adalah daftar harga Jurnal Humaniora dan cetak lepasnya, belum termasuk ongkos kirim.

Daftar harga Jurnal Humaniora dan cetak lepasnya

\begin{tabular}{lll}
\hline Jumlah & $\begin{array}{l}\text { Jurnal Syarikah } \\
\text { (Rp/eksemplar) }\end{array}$ & $\begin{array}{l}\text { Cetak lepasnya*) } \\
\text { (Rp/eksemplar) }\end{array}$ \\
\hline $1-5$ & 75.000 & 30.000 \\
6 atau lebih & 60.000 & 25.000 \\
\hline
\end{tabular}

${ }^{*}{ }^{6}$ pemesanan minimal 5 eksemplar. 


\section{SURAT PERNYATAAN ORISINALITAS ${ }^{1}$}

Kepada

\section{Dewan Editor Jurnal Syarikah}

Program Studi Ekonomi Islam Fakultas Ekonomi islam

Universitas Djuanda Bogor

Bersama ini kami mengajukan naskah,

\section{Judul :}

Penulis:

\begin{tabular}{|c|c|c|c|c|}
\hline No & $\begin{array}{c}\text { Penulis lengkap dengan } \\
\text { gelar akademik }\end{array}$ & Nama dan Alamat Institusi, email & $\begin{array}{l}\text { Tanda } \\
\text { Tangan }\end{array}$ & Tanggal \\
\hline
\end{tabular}

1

2

3

untuk dipublikasikan pada Jurnal Syarikah. Kami menyatakan bahwa naskah dimaksud adalah naskah orisinal hasil penelitian kami yang belum pernah dipublikasikan, tidak sedang dalam proses publikasi oleh media publikasi lainnya, tidak akan diajukan ke media publikasi lainnya selama dalam proses penelaahan (review) kecuali jika kami menarik secara resmi naskah dimaksud dari Dewan Redaksi Jurnal Syarikah, terbebas dari plagiarisme, dan kami bertanggung jawab atas seluruh substansi naskah berjudul tersebut di atas yang kami tulis.

Nama penulis untuk korespondensi:

Telepon/(hanya digunakan untuk keperluan korespondensi)

Email: (untuk keperluan korespondensi dan akan dicantumkan pada artikel yang

dipublikasikan)

Terima kasih atas perhatian dan kerjasamanya.

Tanggal:

Penulis:

Tanda tangan:

\footnotetext{
${ }^{1}$ Dikirim ke Dewan Redaksi Jurnal Syarikah, Program Studi Ekonomi Islam Fakultas Ekonomi Islam Universitas Djuanda Bogor, Gedung B Lantai IV Jl Tol Ciawi No. 1 Kotak Pos 35 Ciawi Bogor 16720, difaksimilikan ke 02518240985, dan hasil scanning-nya diemailkan ke Jurnal.Syarikah@unida.ac.id.
} 


\section{SURAT PERNYATAAN PEMINDAHAN HAK CIPTA ${ }^{2}$}

Yang bertanda tangan di bawah ini adalah penulis naskah yang berjudul:

yang diajukan untuk dipublikasikan pada Jurnal Syarikah: Jurnal Ekonomi Islam ISSN 2442-4420 menyatakan bahwa:

Kami bersedia memindahkan hak publikasi, distribusi, reproduksi, dan menjual naskah kamiyang berjudul tersebut di atas sebagai bagian dari Jurnal Syarikah kepada Dewan Redaksi Jurnal Syarikah ISSN 2442-4420

Demikian surat pernyataan ini saya buat dengan sadar, penuh rasa tanggung jawab, dan tanpa paksaan dari pihak mana pun!

\begin{tabular}{llcc}
\hline No & $\begin{array}{l}\text { Nama Penulis (lengkap } \\
\text { dengan gelar akademik) }\end{array}$
\end{tabular}$\quad$ Nama dan Alamat Institusi, email $\begin{gathered}\text { Tanda } \\
\text { Tangan }\end{gathered}$ Tanggal




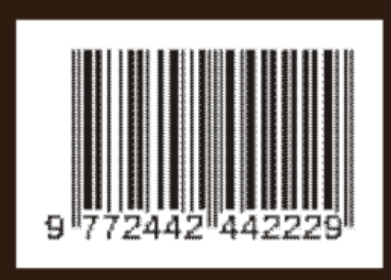

